\title{
RELASI TASAWUF DENGAN PENDIDIKAN KARAKTER
}

\author{
*Dedi Junaedi ${ }^{1)}$ Norcahyono $^{2)}$ \\ 1) IAIN Laa Roiba Bogor, Jawa Barat. Indonesia (dedijunaedi@laaroiba.ac.id) \\ ${ }^{2)}$ Fakultas Agama Islam UM Palangkaraya, Kalimantan Tengah, Indonesia \\ (norcahyono.arribangi@gmail.com)
}

\begin{abstract}
Sufism means reviving the relationship between man and Allah SWT. Awareness of the sense of connection with Allah SWT will place a person to pleasure and mahabbah and ma'rifat, then he will not be disturbed by the changes of time during his life because the center of attention is no longer on those who change, but on those who remain unchanged, that is Allah SWT. Humans in this life need education as a means of communication with those in need. So, in this case, religious education is a very fundamental foundation in achieving the goals both ethically and aesthetically. Takhalli is a way of purifying oneself from reprehensible traits, such as jealousy or envy, suudzan, kibir, ujub, ria, suma ', bakhul, hubbul mal, tafahur, ghadab, ghibah, namimah, kizib, treachery. Then Tahalli by filling himself with praiseworthy attributes such as repentance, khauf, sincerity, gratitude, asceticism, patience, ridha, tawakal, mahabbah, zikrul maut, and getting closer to Allah SWT with four levels of perfection of Islam among them is the first Shari'ah, the second tariqat, the third fact, the fourth ma'rifat. This study discussed what is Sufism and education, how is the relationship between Sufism and education.
\end{abstract}

Keywords: Sufism, Education, Relationship

\begin{abstract}
Abstrak
Bertasawuf berarti menghidupkan hubungan rasa antara manusia dengan Allah SWT. Kesadaran akan rasa berhubungan dengan Allah SWT akan menempatkan seseorang kepada ridha dan mahabbah serta ma'rifat, maka ia tidak akan terganggu oleh perubahan zaman dalam hidupnya, karena pusat perhatiannya tidak lagi pada yang berubah, tetap ia kepada yang tetap tidak berubah yaitu Allah SWT. Manusia dalam kehidupan ini membutuhkan pendidikan sebagai sarana komunikasi dengan yang dibutuhkan. Maka dalam hal ini pendidikan agamalah merupakan landasan yang sangat fundamental dalam mencapai keberhasilan tujuan secara umum baik secara etika maupun estetika. Takhalli merupakan cara membersihkan diri dari sifat-sifat tercela, seperti hasad atau iri hati, dengki, suudzan, kibir, ujub, ria, suma', bakhul, hubbul mal, tafahur, ghadab, ghibah, namimah, kizib, khianat. Kemudian Tahalli dengan mengisi diri dengan sifat-sifat terpuji seperti taubat, khauf, ikhlas, syukur, zuhud, sabar, ridha, tawakal, mahabbah, zikrulmaut, serta mendekatkan diri kepada Allah SWT dengan empat tingkat kesempurnaan agama Islam diantaranya adalah pertama Syariat, kedua tariqat, ketiga hakikat, keempat ma'rifat. Pembahasan dalam penelitian ini; apa itu tasawuf dan pendidikan, bagaimana hubungan antara tasawuf dengan pendidikan.
\end{abstract}

Kata Kunci : Tasawuf, Pendidikan, Hubungan

Cara Mensitasi Artikel:

Junaedi, D., \& Norcahyono, N. (2020). Relasi Tasawuf dengan Pendidikan Karakter. Al-Liqo: Jurnal Pendidikan Islam, 5(02), 161-171. https://doi.org/10.46963/alliqo.v5i02.242

*Corresponding author: dedijunaedi@laaroiba.ac.id

\begin{tabular}{|lc}
\hline & Histori Artikel: \\
Diterima & $: 01 / 12 / 2020$ \\
Direvisi & $:-$ \\
Diterbitkan & $: 28 / 12 / 2020$
\end{tabular}

DOI: https://doi.org/10.46963/alliqo.v5i02.242

This Work is Licensed under (CC-BY-SA) 


\section{PENDAHULUAN}

Pendidikan Agama Islam merupakan sarana untuk bimbingan jasmani dan rohani berdasarkan hukum-hukum Islam menuju kepribadian yang mulia. Pendidikan agama Islam adalah suatu usaha sadar untuk mengasuh dan membina manusia agar senantiasa memahami ajaran Islam secara menyeluruh, lalu menghayati tujuan yang pada akhirnya dapat mengamalkan serta menjadikan Islam sebagai pandangan hidup. Dengan pendidikan Islam, ketentuan-ketentuan hukum yang terdapat di dalam pembelajaran PAI menjadi prioritas penting untuk diwujudkan. Maka hukum-hukum atau syariat yang menjadi bagian dalam pendidikan, tidak boleh dikesampingkan dalam pembentukan manusia berkepribadian baik.

Pembelajaran PAI sangat luas cakupannya dan semua itu memiliki hubungan dengan tasawuf. Muara dari semua tujuan itu tidak lain adalah menjadi hamba Allah SWT yang mulia di sisi-Nya. Pendidikan Islam mengantarkan pada pemahaman yang komprehensif menuju manusia seutuhnya sebagai hamba-Nya sedangkan tasawuf penghambaan yang murni dengan kesucian hati. Tidak ada penghambaan yang murni tanpa pemahaman agama yang baik, dan belum dikatakan baik pemahaman keagamaan bila belum menghambakan diri dengan cara yang baik, Di sinilah hubungan antar keduanya.

Tasawuf yang identik dengan sikap rohani suci yang selalu ingin dekat dengan Tuhan. Apabila dihubungkan dengan pendidikan agama Islam khususnya dalam bidang syariat, maka harus meliputi seluruh aspek hidup dan kehidupan manusia, baik melalui hablum minallah, hablum minannas, maupun hablum minal 'alam, mempunyai hubungan yang sangat erat dan saling mengisi antara satu dengan yang lainnya. Untuk mencapai kemaslahatan dunia dan akhirat dalam arti hakiki harus sepadan, simultan dengan tujuan tasawuf, yaitu melaksanakan hakikat ubudiyah guna memperoleh tauhid yang haqqul yaqin dan makrifatullah yang tahqiq.

Untuk mencapai tujuan tasawuf, seluruh aktivitas syariat harus digerakkan oleh hati nurani yang suci. Pendidikan Islam menjadi salah satu perantara pemahaman hati memberi kontribusi besar terhadap realisasi ajaran tasawuf. 
Hubungan timbal balik ini merupakan hubungan yang harus ada antara tasawuf dengan PAI. Syari'at dilaksanakan oleh anggota tubuh manusia melalui ketentuan-ketentuan yang berlaku, sedangkan powernya melalui rohani batin yang datang langsung dari Allah SWT. Persis kalau dicontohkan ibarat listrik, kabel adalah syari'at-syari'at lahirnya yang dikenalkan melalui pendidikan Agama Islam, sedangkan setrum adalah power melewati kabel yang bersumber dari central dynamo dan tidak bisa dilihat dengan pandangan mata yang Zhahir namun bisa dirasakan keberadaannya.

Dengan mengetahui dan menyadari adanya korelasi antara tasawuf dan pendidikan agama Islam, diharapkan tidak ada upaya untuk memisahkan secara paksa antar masing-masing disiplin ilmu itu. Baik tasawuf, psikologi maupun pendidikan agama Islam sama-sama memiliki objek kajian yang sama yaitu manusia. Begitu juga tasawuf dengan pendidikan agama Islam. Tujuan dari pendidikan agama Islam adalah untuk mewujudkan manusia yang berkepribadian mulia. Tasawuf juga memiliki tujuan sama yaitu menjadi manusia yang mulia di sisi-Nya. Kemuliaan itu, tidak akan pernah tercapai kalau tidak membumikan pesan-pesan moral yang ada dalam pendidikan agama Islam. Itu bisa mewujudkan pesan-pesan moral itu, maka diperlukan kejernihan hati untuk mengamalkan semua itu.

Maka ajaran-ajaran ilmu tasawuf harus diimplementasikan di dalam dunia pendidikan khusus para pendidik karena sangat relevan dengan konteks pendidikan agama Islam di zaman sekarang, mengingat kita butuh pendidik atau pengajar yang sabar, zuhud (tidak memiliki sifat keduniaan), qona'ah (merasa cukup dengan apa yang dimiliki) dan tawakal.

\section{METODE}

Jenis penelitian menggunakan pendekatan deskriptif kualitatif yang penulis gunakan adalah library research yaitu mengumpulkan buku-buku yang berkaitan dengan objek penelitian atau penelitian yang bersifat kepustakaan. 
1. Sumber Data

Kajian yang penulis gunakan adalah penelitian perpustakaan murni, penulis akan menggunakan dua sumber, yaitu:

a. Sumber Primer

Sumber data yang bersifat primer adalah buku rujukan awal dan utama dalam penelitian, sumber primer yang penulis gunakan adalah :

1) A. Mustafa. (1997). Akhlak Tasawuf. Bandung: CV. Pustaka Setia.

2) H.A. Mustafa. (1997). Akhlak Tasawuf. Bandung: Pustaka Setia.

3) Mustafa Zahri. (1997). Kunci Memahami Tasawuf. Surabaya, Pt. Bina Ilmu.

4) Syekh Abdul Qadir Al-Jailani. (2014). Rahasia Besar Sang Guru Besar. Jakarta: Sahara Publishers.

5) Zainur Rofiq Ash-Shodiqy. Biografi Syekh Abdul Qadir Al-Jailani. jombang: darul hikmah,

b. Sumber Sekunder

Sumber sekunder adalah hasil pengumpulan yang dilakukan oleh orang lain dengan maksud tertentu dan mempunyai kategori atau klasifikasi menurut keperluan masing-masing dan kegunaan bagi peneliti masingmasing, S. Nasotion ( 2002: 143)

Dalam hal ini Sumber data yang berifat sekunder adalah buku rujukan pendukung dalam penelitian, sumber sekunder yang penulis gunakan adalah:

1) Lexy J. Moleong. (2013). Metodologi Penelitian Kualitatif. Bandung:Remaja Rosdakarya. Cet. 31

2) Moh. Nazir. (2005). Metode Penelitian. Bogor Selatan: Ghalia Indonesia.

3) Murodi. Sejarah Kebudayaan Islam Madrasah Tsanawiyah Kelas 3. Semarang: PT Karya Toha Putra.

4) Riduwan. (2013). Skala Pengukuran Variabel-Variabel Penelitian. Bandung: Alfabeta. Cet. Ke-10 
5) Riduan. (2015). Belajar Mudah Penelitian Untuk Guru, Karyawan Dan Peneliti Pemula. Bandung: Alfabeta.

6) S. Nasotion. (2002). Metode Research Penelitian Ilmiah. Jakarta: Bumi Aksara. Cet. 5

7) Supiana dan Karman. (2004). Materi Pendidikan Agama Islam. PT. Remaja Rosdakarya.

2. Teknik Pengumpulan Data

Teknik pengumpulan data adalah cara-cara yang digunakan oleh peneliti untuk mengumpulkan data. Pengumpulan data dalam penelitian ini adalah dengan cara dokumentasi. Dokumentasi adalah "ditujukan untuk memperoleh data langsung dari tempat penelitian, meliputi buku-buku yang relevan, peraturan-peraturan, laporan kegiatan, foto-foto, film, dokumenter, data yang relevan penelitian, Riduwan (2013: 24).

3. Teknik Analisa Data

Teknik analisa data adalah cara penghitungan untuk menjawab rumusan masalah dan pengujian hipotesis yang diajukan, Riduan ( 2015: 12). Hipotesis adalah jawaban sementara yang harus di uji kebenarannya. Namun, penelitian yang penulis gunakan dengan kajian pustaka (library research) ini, maka penulis menggunakan teknik analisa data kajian isi (content analysis).

Kajian ini adalah kajian yang memanfaatkan buku atau dokumen untuk menarik kesimpulan, baik kajian isi yang bersifat deduktif maupun kajian isi yang bersifat induktif, Lexy J. Moleong (2013: 220). Pada kajian ini peneliti terlebih dahulu mengadakan survei data untuk memperoleh informasi dari penelitian terdahulu terhadap pengerjaan tanpa memedulikan apakah data itu primer atau sekunder, di lapangan atau di laboratorium. Kemudian, menelusuri literatur yang ada serta menelaahnya secara tekun. Setelah itu, peneliti mengungkapkan buah pikiran secara kritis dan analitis, Moh. Nazir (2005: 93). 


\section{HASIL DAN PEMBAHASAN}

Kata tasawuf dalam ejaan bahasa Indonesia ditulis tasawuf berasal dari kata shafa yang berarti bersih. Jadi, shufi artinya orang yang hatinya tulus dan bersih dihadapan Tuhannya, Supiana dan Karman (2004: 217). Pendapat lain mengatakan, tasawuf menurut bahasa تصوف - يتصوف - تصوفا artinya seseorang laki-laki telah berpindah halnya dari kehidupan biasa kepada kehidupan sufi, H.A. Mustafa (1997: 201). jadi, tasawuf adalah "orang yang menyucikan dirinya lahir dan bathin dalam suatu pendidikan budi pekerti dengan menempuh jalan atas dasar didikan tiga tingkatan yaitu takhalli, tahalli, dan tajalli" Mustafa Zahri (1997: 30).

Takhalli merupakan cara membersihkan diri dari sifat-sifat tercela (kotoran hati),seperti hasad atau iri hati, haqad atau dengki atau benci, suudzan, kibir ( sombong), ujub (merasa sempurna), ria, suma' (cari nama), bakhul, hubbul mal (cinta kebendaan), tafahur (membanggakan diri), ghadab (pemarah), ghibah, namimah (bicara dibelakang), kizib (dusta), khianat (munafik).

Tahalli merupakan mengisi diri dengan sifat-sifat terpuji (menyinari hati) maksudnya adalah melakukan perbaikan akhlak serta menanamkan sifat-sifat yang menyinari hati seperti taubat, khauf (taqwa), ikhlas, syukur, zuhud (hidup sederhana), sabar, ridha (menerima keputusan Allah SWT), tawakal, mahabbah, zikrulmaut (selalu mengingat akan mati), serta mendekatkan diri kepada Allah SWT dengan empat tingkat kesempurnaan agama islam diantaranya adalah pertama Syariat, kedua tariqat, ketiga hakikat, keempat ma'rifat.

Tajalli (kenyataan Tuhan) dalam tasawuf yaitu para shufi mengadakan riadhah( latihan-latihan) jiwa berusaha melepaskan pada dirinya serta mengosongkan qalbunya dari sifat-sifat tercela (Takhalli) dan mengisinya dengan sifat sifat yang terpuji (tahalli) serta memutuskan segala hubungan yang dapat merugikan kesucian dirinya dalam keadaan mana memepersiapkan dirinya untuk menerima pancaran nur cahaya Allah itu, Mustafa Zahri (1997: 62-79).

Menurut Syekh Abdul Qadir Al-jailani "tasawuf adalah suatu ilmu yang setiap materinya dapat mengantarkan seseorang sampai kepada Allah SWT, baik materi yang terkait dengan akhlak sufinya, ma'rifatnya, maupun suluknya yang 
mencakup masalah penyikapan, penyaksian, dan pengalaman spiritual langsung atas penampakan diri Allah SWT dan tarikan-tarikan-Nya kepada mereka" Syekh Abdul Qadir Al-Jailani (2014: 8).

Tasawuf hanyalah sebatas materi yang ditambahkan kepada syariat, sebagaimana energi. bagi syariat, ia laksana roh dalam tubuh. sehingga, ketika cahaya tasawuf telah menyinari hati seorang hamba, maka keikhlasan akan memancar dalam amalannya, hatinya akan terkait dengan sang Khaliq, dan rohnya akan tertarik untuk bersatu dengan dunia pertamanya yang suci. kemudian, roh akan diwarnai oleh kerinduan yang mendalam kepada dunia tersebut karena kedekatannya dengan sang Khaliq. ia dipersenjatai oleh semangat harapan dan rasa takut dalam pengasingan dirinya dari semua makhluk, dan keterikatannya dengan sang Khaliq. ia akan menjadi zuhud, wara', bertakwa, lalu merasakan kenyamanan, mengenal sanga maha benar, dan akhirnya tenggelam dalam penafian dirinya dari segala sesuatu selain Allah SWT.

Tasawuf dapat dilalui dengan beberapa tahapan-tahapan atau yang disebut dengan maqam. maqam-maqam ini diantaranya zuhud, mahabbah, ma'rifat, fana dan baqa, ittihad dan hulul, Murodi (1997: 38).

1. Zuhud yaitu kehidupan yang telah terbebas dari materi duniawi. setelah tahapan inilah seseorang bisa meningkatkan dirinya menjadi sufi.

2. Mahabbah adalah paham tasawuf yang menekankan perasaan cinta kepada Tuhan.

3. Ma'rifah adalah hadirnya kebenaran Allah pada sufi dalam keadaan hatinya selalu berhubungan dengan Nur ilahi.

4. Fana dan Baqa Fana merupakan proses menghancurkan diri bagi seorang sufi agar dapat bersatu dengan Tuhan. Sedangkan baqa adalah sifat yang mengiringi dari proses fana dalam penghancuran diri untuk mencapai ma'rifah.

5. Ittihad dan hulul

Ittihad merupakan suatu tingkatan di mana yang mencintai dan yang dicintai telah menjadi satu. kemudian, salah satu dari mereka dapat memanggil yang satu lagi dengan perkataan: Hai aku. sedangkan hulul adalah paham yang mengatakan Tuhan memilih tubuh-tubuh manusia tertentu untuk mengambil 
tempat di dalamnya, setelah sifat-sifat kemanusiaan yang ada di dalam tubuh itu dilenyapkan.

Orang yang sudah ahli dalam tasawuf, mereka masuk surga tanpa dihisab. Mereka itu adalah golongan Ahlus Sunah Wal Jama'ah, yaitu orang-orang yang perbuatan dan perkataannya sesuai dengan syariat dan tarekat, yang disebut dengan As-Sunniyyun.

\section{Hubungan Tasawuf dengan Pendidikan}

Tasawuf bertujuan untuk memperoleh suatu hubungan khusus langsung dari Tuhan. dengan kesadaran, bahwa manusia sedang berada di hadirat Tuhan. kesadaran tersebut akan menuju kontak komunikasi dan dialog antara ruh manusia dengan Tuhan. hal ini melalui cara bahwa manusia perlu mengasingkan diri.

Tasawuf adalah suatu ilmu yang mempelajari suatu cara bagaimana seseorang dapat mudah berada di hadirat Allah SWT. tasawuf beresensi pada hidup dan berkembang mulai dari bentuk hidup "kezuhudan" (menjauhkan kemewahan duniawi), dalam bentuk "tasawuf amali" kemudian "tasawuf falsafi", A. Mustafa (1997: 206). Tasawuf adalah aspek ajaran Islam yang paling penting, karena merupakan jantung atau urat nadi pelaksanaan ajaran-ajaran Islam. tasawuf inilah yang merupakan kunci kesempurnaan amaliah ajaran Islam.

Agama terdiri dari tiga aspek kesatuan, yaitu Islam, iman, dan ihsan. untuk mengetahui hukum Islam kita harus lari kepada syariat/fiqih, untuk mengetahui rukun iman kita harus lari pada Ushuluddin/akidah dan untuk mengetahui kesempurnaan ihsan kita masuk ke dalam tasawuf. oleh karena itu, tasawuf adakalanya membawa orang menjadi sesat dan musyrik apabila seseorang bertasawuf tanpa bertauhid dan bersyariat.

Tasawuf adalah suatu kehidupan rohani yang merupakan fitrah manusia dengan tujuan untuk mencapai hakikat yang tinggi, berada dekat atau sedekat mungkin dengan Allah dengan jalan menyucikan jiwanya, dengan melepaskan jiwanya dari kungkungan jasadnya yang menyadarkan hanya pada kehidupan kebendaan, serta melepaskan jiwanya dari noda-noda sifat dan perbuatan yang tercela. oleh sebab itu, tasawuf adalah jalan spiritual dan merupakan dimensi batin, yaitu ilmu agama, khusus berkaitan dengan aspek-aspek moral serta tingkah 
laku yang merupakan substansi Islam. hakikat tasawuf adalah perpindahan sikap mental, keadaan jiwa dari suatu keadaan kepada keadaan yang lain yang lebih tinggi dan lebih sempurna, suatu perpindahan dari alam kebendaan kepada alam rohani.

Orang tasawuf hidup seperti mana orang pada umumnya, mempunyai harta benda, makan dengan makanan yang enak-enak, memakai pakaian yang bagusbagus, tidur di atas kasur yang empuk, dan sebagainya. semua itu dilakukan untuk mendekatkan diri kepada Allah SWT.

Firman Allah SWT dalam surah Al-Munafiqun ayat 9 yang berbunyi :

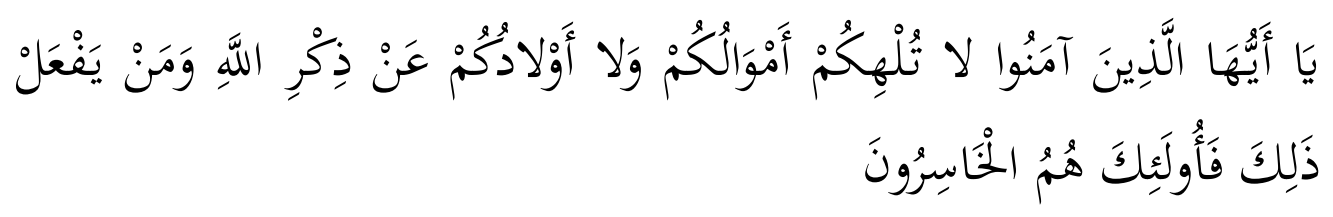

Artinya: Hai orang-orang beriman, janganlah hartamu dan anak-anakmu melalaikan kamu dari mengingat Allah. Barang siapa yang berbuat demikian Maka mereka Itulah orang-orang yang merugi.(Q.S. Al-Munafiqun ayat 9)

Akan tetapi apabila sesuatu, termasuk dunia itu memperkuat ibadah mereka terhadap Allah, apalagi itu perintah Allah dan Rasul-Nya, merekapun akan mengambilnya. sikap ini dilandaskan pada Al-Qur'an dan Hadis seperti firman Allah SWT dalam surah Al-Qashash ayat 77 yang berbunyi :

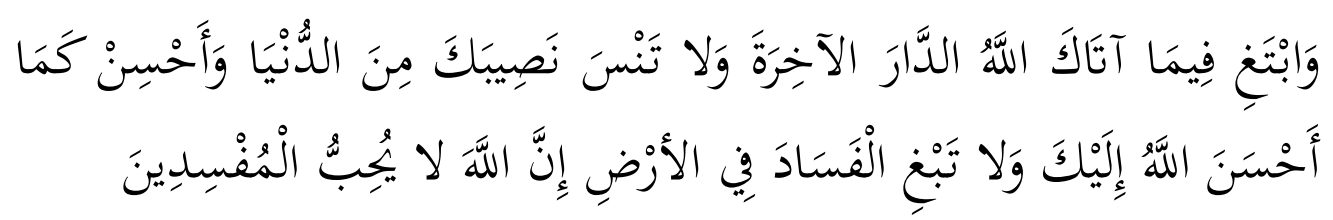

Artinya: Dan carilah pada apa yang telah dianugerahkan Allah kepadamu (kebahagiaan) negeri akhirat, dan janganlah kamu melupakan bahagianmu dari (kenikmatan) duniawi dan berbuat baiklah (kepada orang lain) sebagaimana Allah telah berbuat baik, kepadamu, dan janganlah kamu berbuat kerusakan di (muka) bumi. Sesungguhnya Allah tidak menyukai orang-orang yang berbuat kerusakan.(Q.S. Al-Qashash ayat 77) 
Firman Allah SWT dalam surah Al-Baqarah ayat 60 yang berbunyi :

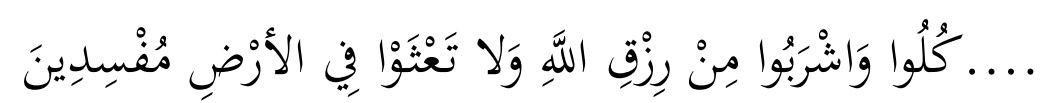

Artinya: Makan dan minumlah rezeki (yang diberikan) Allah, dan janganlah kamu berkeliaran di muka bumi dengan berbuat kerusakan.(Q.S. Al-Baqarah ayat 60$)$

Sabda Nabi Muhammad SAW yang artinya : "Bukanlah orang baik jika engkau tinggalkan dunia untuk akhirat atau sebaliknya meninggalkan akhirat untuk dunia. hendaklah mencapai kedua-duanya karena dunia itu jalan ke akhirat dan jangan kamu bergantung pada manusia" (Riwayat Ibn As-Sakir). Jadi, orang yang menjalani hidup tasawuf itu bukan berarti harus hidup miskin, tetapi yang lebih penting hati tidak terkait oleh harta kekayaan yang kita miliki dan tetap terpaut dengan Allah SWT. Bisa jadi orang miskin harta, tetapi hatinya tetap memikirkan dunia, Zainur Rofiq Ash-Shodiqy (2014: 63-64).

\section{KESIMPULAN}

Tasawuf identik dengan sikap rohani yang selalu ingin dekat dengan Tuhan. Apabila dihubungkan dengan pendidikan agama Islam khususnya dalam bidang syariat, maka harus meliputi seluruh aspek kehidupan manusia, baik melalui hablum minallah, hablum minannas, maupun hablum minal 'alam, yang mempunyai hubungan yang sangat erat untuk salung mengisi antara satu dengan yang lainnya untuk mencapai kemaslahatan dunia dan akhirat dalam arti harus sepadan.

Dengan mengetahui dan menyadari adanya korelasi antara tasawuf dengan pendidikan agama Islam khususnya, diharapkan tidak ada lagi upaya untuk memisahkan secara paksa antar masing-masing disiplin ilmu. Baik ilmu tasawuf maupun ilmu tentang pendidikan secara umum, karena tujuan dari ilmu adalah menyampaikan pesan-pesan moral, maka diperlukan kejernihan hati untuk menerima dan berusaha diamalkan dengan segenap kemampuan. Maka ajaranajaran ilmu tasawuf dalam dunia pendidikan khusus para pendidik sangat relevan 
dengan konteks pendidikan pada zaman ini, mengingat kita sangat membutuhkan sifat-sifat terpuji dan terhindar dari sifat-sifat tercela.

\section{REFERENSI}

A. Mustafa. (1997). Akhlak Tasawuf. Bandung: CV. Pustaka Setia.

H. A. Mustafa. (1997). Akhlak Tasawuf. Bandung:Pustaka Setia.

Lexy J. Moleon. (2013). Metodologi Penelitian Kualitatif. Bandung:Remaja Rosdakarya. Cet. 31

Moh. Nazir. (2005). Metode Penelitian. Bogor Selatan: Ghalia Indonesia.

Mustafa Zahri. (1997). Kunci Memahami Tasawuf. Surabaya, Pt. Bina Ilmu.

Murodi. Sejarah Kebudayaan Islam Madrasah Tsanawiyah Kelas 3. Semarang: PT Karya Toha Putra.

Riduwan. (2013). Skala Pengukuran Variabel-Variabel Penelitian. Bandung: Alfabeta. Cet. Ke-10

Riduan. (2015). Belajar Mudah Penelitian Untuk Guru, Karyawan Dan Peneliti Pemula. Bandung: Alfabeta.

S. Nasotion. (2002). Metode Research Penelitian Ilmiah. Jakarta: Bumi Aksara. Cet. 5

Supiana dan Karman. (2004). Materi Pendidikan Agama Islam. PT. Remaja Rosdakarya.

Syekh Abdul Qadir Al-Jailani. (2014). Rahasia Besar Sang Guru Besar. Jakarta: Sahara Publishers.

Zainur, R, A. (n.d)). biografi syekh Abdul Qadir Al-Jailani, Jombang: Darul hikmah. 